\title{
Pewarnaan Simpul Dengan Algoritma Welch-Powell Pada Traffic Light di Yogyakarta
}

\author{
Ana Mardiatus Soimah dan Noor Saif Muhammad Mussafi \\ Program Studi Matematika Fakultas Sains dan Teknologi, UIN Sunan Kalijaga, Jl. Marsda Adisucipto \\ No. 1 Yogyakarta, Indonesia \\ Korespondensi; Ana Mardiatus Soimah, Email: anapri_soimah@yahoo.com
}

\begin{abstract}
Abstrak
Kemacetan lalu lintas merupakan masalah yang sering dijumpai di kota-kota besar di Indonesia. Ini membutuhkan berbagai solusi, salah satunya dengan setting lampu lalu lintas. Penataan lampu lalu lintas bisa dilengkapi dengan teori grafik. Bagian dari teori graf adalah pewarnaan grafik yang digunakan. Pewarnaan graf tiga yaitu pewarnaan dibedakan menjadi simpul, pewarnaan sisi, dan daerah pewarnaan. Penelitian ini meneliti pengaturan tentang lampu lalu lintas menggunakan algoritma pewarnaan Welch simpul dengan Powell. Persimpangan Data diwakili dalam grafik, yang kemudian dipecahkan dengan mewarnai simpul, kemudian mencari nilai durasi efektif waktu dibandingkan dengan setting lampu lalu lintas yang terjadi di beberapa persimpangan di Yogyakarta. Penyelesaian pengaturan lampu lalu lintas dengan menggunakan node pewarnaan memberikan solusi alternatif durasi menyalakan lampu merah dan lampu hijau lebih efektif daripada data sekunder di beberapa persimpangan di Yogyakarta.
\end{abstract}

Kata Kunci: Algoritma; Knot pewarnaan Welch Powell; Setting lampu lalu lintas

\begin{abstract}
Traffic congestion is a problem which is often found in big cities in Indonesia. This requires a range of solutions, one of them with the settings of the traffic light. Traffic light arrangement can be completed with graph theory. Part of graph theory a graph coloring is used. Staining graf three i.e. coloring is differentiated into a knot, staining the sides, and staining region. This research examines the arrangements about traffic light using colorization algorithm Welch knot with Powell. The intersection of Data represented in the graph, which is then solved by coloring the vertices, then look for the value of the effective duration of the time compared to a traffic light settings occur at several intersections in Yogyakarta. Completion of traffic light arrangement using staining nodes provide alternative solutions duration lit the red light and green light is more effective than the secondary data at several intersections in Yogyakarta.
\end{abstract}

Keywords: Algorithm, Knot staining Welch Powell; Setting up a traffic light

\section{Pendahuluan}

Kemacetan lalu lintas merupakan masalah yang sering dijumpai di kota-kota besar di Indonesia. Beberapa faktor penyebab kemacetan adalah kurangnya disiplin pengguna jalan dan volume kendaraan yang semakin bertambah. Hal ini memerlukan berbagai macam penyelesaian, salah satunya dengan pengaturan lampu lalu lintas (traffic light). Masalah pengaturan traffic light merupakan masalah pengaturan arus kendaraan pada suatu simpang jalan serta pengaturan siklus waktu lampu merah dan lampu hijau. Pada persimpangan jalan banyak ditemui traffic light dengan durasi lampu hijau yang singkat dan lampu merah yang lama. Hal ini menyebabkan terjadinya peningkatan antrian kendaraan pada persimpangan tersebut. Durasi lampu merah yang lama juga mengakibatkan masa tunggu menjadi lama.

Penyelesaian masalah traffic light dapat ditinjau dalam perspektif graf, yaitu dengan merepresentasikan persimpangan dalam bentuk graf. Simpul graf menunjukkan arah perjalanan yang diperbolehkan dari jalan $\mathrm{X}$ menuju jalan $\mathrm{Y}$, sedangkan sisi graf menunjukkan arah perjalanan yang 
tidak boleh dilakukan secara bersamaan. Selanjutnya menyelesaikannya dengan metode pewarnaan simpul menggunakan algoritma Welch-Powell. Penyelesaian ini akan menghasilkan arus-arus yang dapat berjalan secara bersamaan, selain itu juga diperoleh alternatif durasi siklus baru. Durasi siklus baru ini akan dibandingkan dengan siklus waktu data sekunder dari Dinas Perhubungan Yogyakarta tahun 2011 dan diharapkan bisa menjadi solusi bagi pengguna jalan dalam rangka mempercepat masa tunggu ketika lampu merah menyala.

\section{Dasar Teori}

\section{Graf}

1. Definisi Graf

Menurut [1], sebuah graf $G$ terdiri dari suatu himpunan $V$ yang merupakan vertex-vertex (simpulsimpul) dan suatu himpunan $E$ dari sisi-sisi sedemikian rupa sehingga setiap sisi $e \in E$ dikaitkan dengan pasangan simpul tak terurut. Jika terdapat sebuah rusuk $e$ yang menghubungkan simpul $v$ dan $w$, dapat dinyatakan dengan $e=(v, w)$ atau $e=(w, v)$. Dalam konteks ini, $(v, w)$ menyatakan sebuah sisi antara simpul $v$ dan simpul $w$ dalam sebuah graf dan buka sebuah pasangan terurut. Misal $G$ adalah graf dengan himpunan simpul $V(G)=\{a, b, c, d, e\}$ dan $E(G)=$ $\{(a, b),(b, c),(c, d),(d, e),(e, a),(e, b),(e, c),(d, b)\}$. Graf $\mathrm{G}$ dapat disajikan dalam bentuk gambar yaitu pada Gambar 1a ataupun Gambar $1 b$.

2. Pewarnaan Simpul

Misalkan $G$ adalah graf dan $k$ adalah bilangan bulat positif. Suatu pewarnaan- $k$ untuk graf $G$ adalah cara mewarnai simpul pada graf $G$ dengan paling banyak $k$ warna sedemikian sehingga simpul yang adjacent (bertetangga) diwarnai dengan warna yang berbeda. Contoh pewarnaan simpul disajikan pada Gambar 1a.

3. Bilangan Kromatik (Chromatic Number)

Misalkan $G$ adalah graf. Bilangan Kromatik (chromatic number) dari graf $G$ dinyatakan dengan $x(G)$ adalah jumlah warna minimum yang digunakan untuk mewarnai simpul pada graf $G$ sedemikian sehingga simpul yang adjacent diwarnai dengan warna yang berbeda [2]. Graf $G$ pada Gambar 1a mempunyai bilangan kromatik $x(G)=4$.

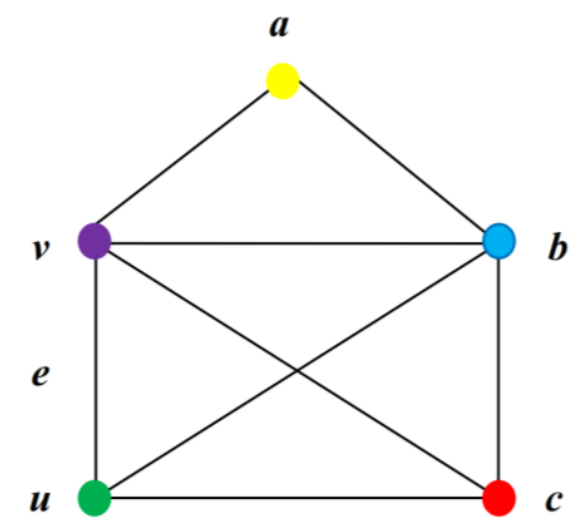

(a)

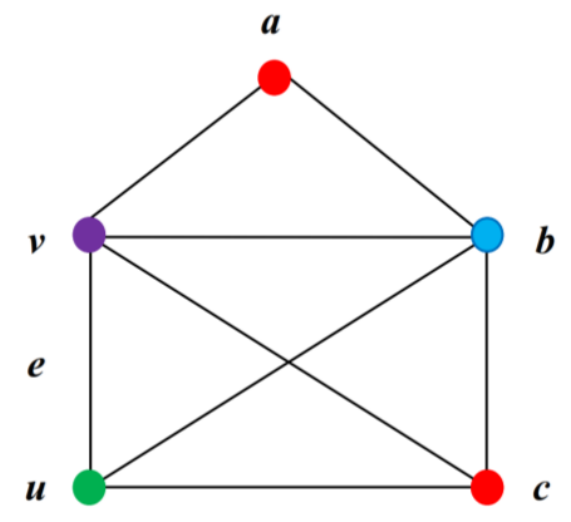

(b)

Gambar 1 (a) Graf G, (b) Pewarnaan simpul Graf G dengan kaidah bilangan kromatik.

\section{Algoritma Welch-Powell}

Algoritma Welch-Powell digunakan untuk mewarnai simpul suatu graf berdasarkan derajat tertinggi dari simpul-simpulnya. Algoritma Welch-Powell merupakan algoritma yang tergolong dalam algoritma Greedy. Algoritma Greedy yaitu algoritma yang pada setiap langkah penyelesaian terdapat banyak pilihan solusi yang perlu dieksplorasi. Pada setiap langkah harus diputuskan pilihan terbaik yang 
selanjutnya akan menjadi solusi optimum local (locally optimal) dan diharapkan dapat menjadi solusi optimum global (globally optimal).

Selain algoritma Welch-Powell, algoritma Kruskals dan algoritma Prims untuk menyelesaikan masalah Minimum Spanning Tree juga tergolong dalam algoritma Greedy. Menurut [3], algoritma Welch-Powell adalah sebagai berikut:

1. Urutkan simpul-simpul dari graf $G$ dalam derajat yang menurun (urutan seperti ini mungkin tidak unik karena beberapa simpul mungkin berderajat sama).

2. Gunakan satu warna untuk mewarnai simpul pertama (yang mempunyai derajat tertinggi) dan simpul-simpul lain (dalam urutan yang berurut) yang tidak bertetangga dengan simpul pertama ini.

3. Mulai lagi dengan simpul derajat tertinggi berikutnya di dalam daftar terurut yang belum diwarnai dan ulangi proses pewarnaan simpul dengan menggunakan warna kedua.

4. Ulangi penambahan warna-warna sampai semua simpul telah diwarnai.

Algoritma Welch-Powell tidak selalu memberikan jumlah warna minimum pada suatu pewarnaan graf, tetapi algoritma ini memberikan batas atas jumlah warna yang dapat dipakai untuk mewarnai suatu graf.

\section{Pewarnaan Simpul dengan Algoritma Welch-Powell}

Seperti yang dijelaskan sebelumnya, misalkan $G$ adalah graf sederhana. Suatu pewarnaan-k untuk graf $G$ adalah penggunaan sebagian atau semua $k$ warna untuk mewarnai semua simpul pada graf $G$ sehingga dua simpul yang terhubung langsung diberi warna yang berbeda. Jika $G$ mempunyai pewarnaan - $k$ selanjutnya graf $G$ dikatakan dapat diwarnai dengan $k$ - warna $(k-$ colourable). Pemberian warna pada simpul dapat direpresentasikan dengan angka atau dapat juga direpresentasikan langsung menggunakan warna misalnya merah, hijau, biru, kuning dan lain-lain. Masalah utama dalam pewarnaan simpul adalah pencarian solusi penggunaan jumlah warna yang seminimal mungkin. Jumlah warna yang paling minimal yang digunakan untuk mewarnai graf disebut dengan bilangan kromatik (chromatic number).

\section{Pembahaan}

\section{Aplikasi Pewarnaan Simpul pada Traffic Light di Persimpangan Jalan}

Traffic light yang tersedia di persimpangan jalan mempunyai beberapa tujuan antara lain menghindari hambatan karena adanya perbedaan arus jalan bagi pergerakan kendaraan, memfasilitasi pejalan kaki agar dapat menyebrang dengan aman, dan mengurangi tingkat kecelakaan yang diakibatkan oleh tabrakan karena perbedaan arus jalan. Namun traffic light juga memiliki beberapa permasalahan yang perlu segera diselesaikan, salah satunya pengaturan durasi lampu merah dan hijau. Permasalahan ini dapat dikaji pengaturannya menggunakan prinsip pewarnaan simpul. Untuk lebih jelasnya berikut adalah langkah-langkah aplikasi pewarnaan simpul pada traffic light di persimpangan jalan.

1. Mentransformasi persimpangan jalan beserta arusnya ke bentuk graf. Simpul merepresentasikan arus dan garis merepresentasikan arus-arus yang uncompatible, artinya arus-arus yang tidak boleh berjalan bersamaan, yang selanjutnya simpul-simpul tersebut saling dihubungkan.

2. Mewarnai setiap simpul pada graf dengan menggunakan algoritma Welch-Powell. Selain untuk mengetahui arus mana saja yang bisa berjalan bersamaan, diperoleh juga jumlah bilangan kromatik yang akan bermanfaat pada tahap berikutnya.

3. Menentukan alternatif penyelesaian durasi lampu hijau dan lampu merah menyala dengan siklus waktu tertentu, caranya dengan membagi satu siklus yang terdiri dari total durasi lampu merah dan lampu hijau menyala dengan bilangan kromatik yang telah diperoleh dari langkah 2, hasil pembagiannya menunjukkan durasi lampu hijau menyala. Adapun durasi siklus waktu pada setiap persimpangan yang diteliti merujuk pada data sekunder dari Dinas Perhubungan Daerah Istimewa Yogyakarta tahun 2011. 
Berikut akan dipaparkan salah satu penyelesaian kasus pengaturan traffic light yaitu pada traffic light di simpang 5 Terminal Giwangan.

Berikut ini diberikan ilustrasi jalan pada simpang 5 Giwangan.

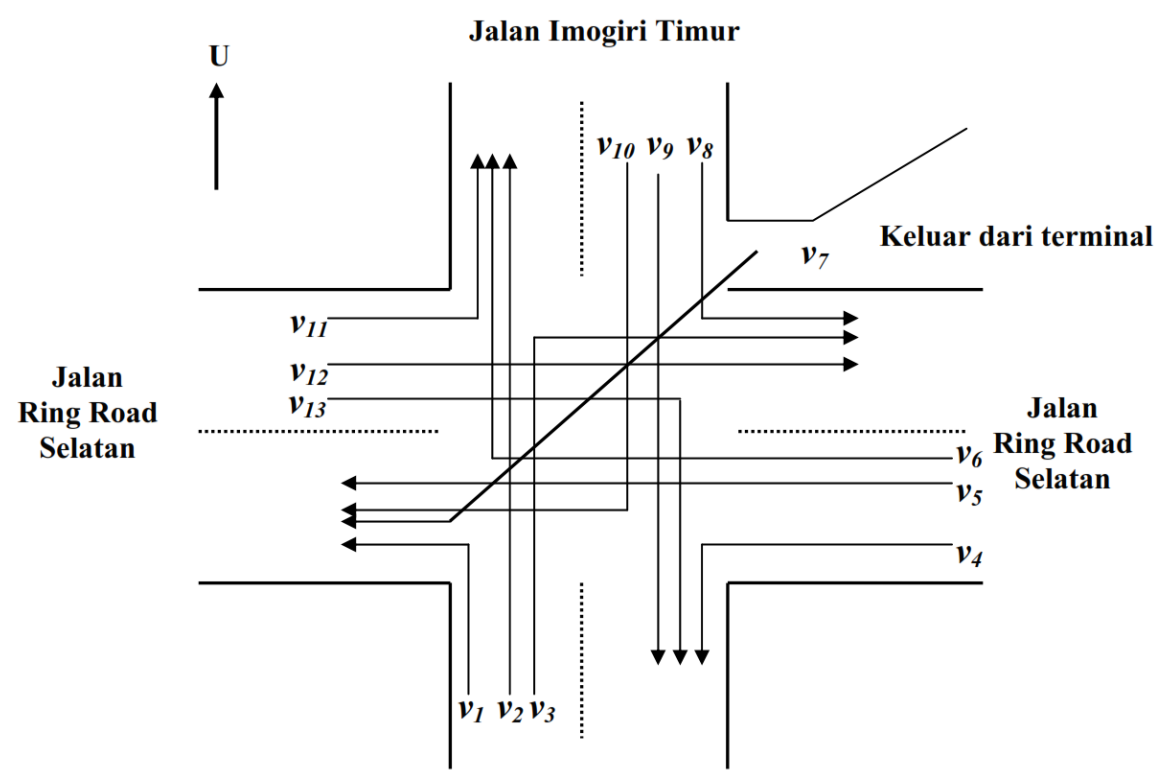

Jalan Imogiri Timur

Gambar 2 Ilustrasi arus simpang 5 Giwangan.

Dari ilustrasi Gambar 3 dengan berpedoman pada langkah-langkah yang telah dipaparkan sebelumnya maka diperoleh hasil transformasi graf sebagai berikut:

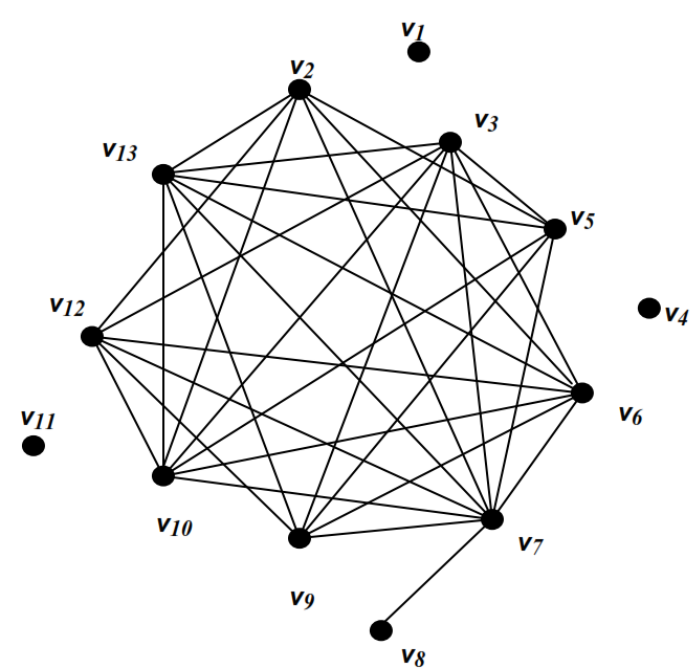

Gambar 3 Graf simpang 5 Giwangan.

Dari transformasi graf di atas terlihat simpul $v_{1}, v_{4}, v_{11}$ tidak saling terhubung dengan simpul lain (simpul asing), ini berarti arus yang dinyatakan oleh $v_{1}, v_{4}, v_{11}$ dapat berlangsung beriringan dengan arus lain. Jadi, untuk arus yang dinyatakan oleh $v_{1}, v_{4}, v_{11}$ selalu berlaku lampu hijau. Selanjutnya untuk simpul yang tersisa akan diberi warna dengan algoritma Welch-Powell. Pewarnaan simpul yang dihasilkan dapat dilihat pada Gambar 4 berikut ini. 


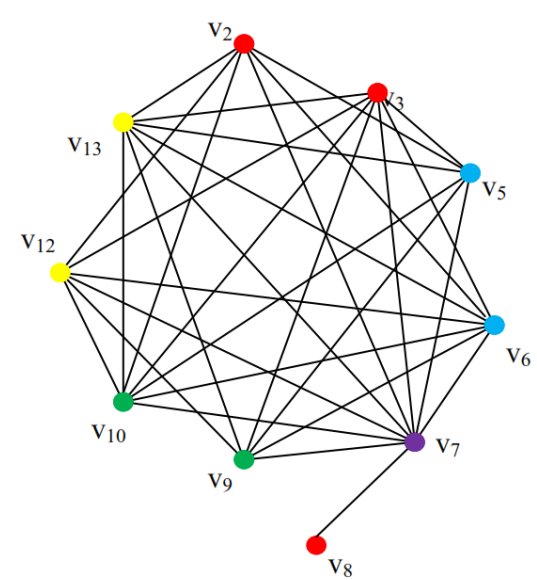

Gambar 4 Hasil pewarnaan graf simpang 5 Giwangan.

Dari pewarnaan graf di atas diperoleh bilangan kromatik $=5$, simpul $v_{8}$ tidak saling adjacent (bertetangga) dengan simpul $v_{2}, v_{3}, v_{5}, v_{6}, v_{9}, v_{10}, v_{12}$ dan $v_{13}$ sehingga warna simpul $v_{8}$ bisa diseragamkan dengan simpul $v_{2}, v_{3}, v_{5}, v_{6}, v_{9}, v_{10}, v_{12}$ atau $v_{13}$. Hal ini akan berpengaruh pada penyelesaian arus yang dapat berjalan secara bersamaan. Berikut rinciannya

1. Partisi pertama arus $v_{2}$ akan berjalan bersama dengan arus $v_{3}$ dan $v_{8}$.

2. Partisi kedua arus $v_{5}$ akan berjalan bersama dengan arus $v_{6}$ dan $v_{8}$.

3. Partisi ketiga arus $v_{7}$ akan berjalan sendiri.

4. Partisi keempat arus $v_{9}$ akan berjalan bersama dengan arus $v_{8}$ dan $v_{10}$.

5. Partisi keempat arus $v_{12}$ akan berjalan bersama dengan arus $v_{8}$ dan $v_{13}$.

Menentukan alternatif penyelesaian durasi lampu merah dan lampu hijau menyala. Diberikan data traffic light di simpang 5 Giwangan dari Dinas Perhubungan Provinsi Daerah Istimewa Yogyakarta sebagai berikut:

Tabel 1 Tabel data sekunder simpang 5 Giwangan.

\begin{tabular}{ccccccc}
\hline Kaki Simpang & Utara & Timur & Selatan & Barat & Terminal & Total \\
\hline Merah & 124 & 120 & 123 & 120 & 125 & 612 \\
Hijau & 23 & 27 & 24 & 27 & 22 & 123 \\
Total & 147 & 147 & 147 & 147 & 147 & 735 \\
\hline
\end{tabular}

Menurut data di atas satu siklus traffic light berdurasi 147 detik, setelah dilakukan pembagian dengan bilangan kromatik $=5$ diperoleh durasi lampu hijau menyala yaitu 29.4 detik dan durasi lampu merah menyala yaitu 117.6 detik. Terkecuali untuk arus $v \boldsymbol{B}$, karena arus ini dapat berjalan bersamaan dengan 4 partisi yang lain maka durasi lampu hijau menyala menjadi 117.6 detik dan durasi lampu merah menyala menjadi 29.4 detik. Data traffic light baru hasil perhitungan disajikan sebagai berikut:

Tabel 2 Tabel data baru traffic light simpang 5 Giwangan.

\begin{tabular}{ccccccc}
\hline Kaki Simpang & Utara & Timur & Selatan & Barat & Terminal & Total \\
\hline Merah & 117.6 & 117.6 & 117.6 & 117.6 & 117.6 & 588 \\
Hijau & 29.4 & 29.4 & 29.4 & 29.4 & 29.4 & 147 \\
Total & 147 & 147 & 147 & 147 & 147 & 735 \\
\hline
\end{tabular}

Tingkat efektifitas erat kaitannya dengan rasio atau perbandingan. Rasio menunjukkan ukuran relatif dari dua atau lebih nilai. Rasio dapat dinyatakan dalam desimal, persentase, ataupun pecahan. 
Dalam penelitian ini tingkat efektifitas diperoleh dari rasio jumlah durasi lampu merah dan lampu hijau menyala antara hasil penyelesaian pewarnaan simpul dengan algoritma Welch-Powell dan data sekunder dari Dinas Perhubungan, Daerah Istimewa Yogyakarta tahun 2011.

\section{Tingkat efektifitas pada simpang 5 Giwangan}

1. Durasi total lampu hijau menyala dari data sekunder adalah 123 detik sementara dengan pewarnaan simpul durasi total lampu hijau menyala adalah 147 detik. Tingkat efektifitasnya adalah Hijau = [(147-123)/123] x 100\% = 19,51\%

2. Durasi total lampu merah menyala dari data sekunder adalah 612 detik sementara dengan pewarnaan simpul durasi total lampu merah menyala adalah 588 detik. Tingkat efektifitasnya adalah Merah $=[(599-612) / 599] \times 100 \%=3,92 \%$

Jadi, untuk kasus pada simpang 5 Giwangan durasi lampu hijau menyala akan meningkat sebesar $19.51 \%$, sedangkan durasi lampu merah menyala dapat dikurangi sebesar $3.92 \%$.

Dengan cara yang analog berikut disajikan tabel tingkat efektifitas durasi traffic light dari kasus beberapa persimpangan jalan di Daerah Istimewa Yogyakarta.

Tabel 3 Tabel tingkat efektifitas.

\begin{tabular}{clcc}
\hline No. & Nama Simpang & Merah & Hijau \\
\hline 1. & Simpang 3 Gamping & $20.39 \%$ & $47.10 \%$ \\
2. & Simpang 3 Bandara & $20.33 \%$ & $46.83 \%$ \\
3. & Simpang 3 Bantulan & $26.04 \%$ & $78.64 \%$ \\
4. & Simpang 3 Maguwo & $3.39 \%$ & $4.59 \%$ \\
5. & Simpang 3 Raden Ronggo & $20.64 \%$ & $48.17 \%$ \\
6. & Simpang 4 Ketandan & $7.14 \%$ & $30 \%$ \\
7. Simpang 4 Wojo & $5.9 \%$ & $23.21 \%$ \\
8. & Simpang 4 Karang Turi & $5.73 \%$ & $22.31 \%$ \\
9. Simpang 4 Druwo & $6.16 \%$ & $24.51 \%$ \\
10. Simpang 4 Kasihan & $6.45 \%$ & $26.08 \%$ \\
11. Simpang 4 Gejayan & $6.07 \%$ & $14.85 \%$ \\
12. Simpang 4 Gramedia & $7.14 \%$ & $18.18 \%$ \\
13. Simpang Kreliring & $-4.82 \%$ & $-3.33 \%$ \\
14. Simpang 5 Giwangan & $3.92 \%$ & $19.51 \%$ \\
15. Simpang 5 Pojok Benteng Kulon & $3.85 \%$ & $19.09 \%$ \\
\hline
\end{tabular}

Pada kasus simpang Kleringan tanda (-) menunjukkan bahwa penyelesaian menggunakan pewarnaan simpul tidak lebih efektif dari pada data yang ada di lapangan.

\section{Kesimpulan}

Berdasarkan pembahasan pada bab-bab sebelumnya, diperoleh kesimpulan sebagai berikut:

1. Pewarnaan simpul dengan algoritma Welch-Powell dapat diaplikasikan untuk menyelesaikan perhitungan durasi waktu pada traffic light. Langkah yang ditempuh yaitu dengan mentransformasi persimpangan jalan beserta arusnya ke bentuk graf. Simpul merepresentasikan arus dan garis merepresenrasikan arus yang uncompatible. Selanjutmya mewarnai simpul pada graf dengan algoritma Welch-Powell untuk mengetahui arus yang dapat berjalan bersamaan dan memperoleh bilangan kromatik yang berfungsi untuk menentukan alternatif penyelesaian durasi waktu traffic light

2. Penyelesaian perhitungan durasi waktu pada traffic light dengan pewarnaan simpul memberikan alternatif hasil yang lebih efektif hingga $78.64 \%$ daripada data sekunder dari Dinas Perhubungan Yogyakarta tahun 2011. 


\section{Referensi}

[1] Johnsoundbaugh, Richard. 2002. Matematika Diskrit. Jakarta: PT Prenhallindo.

[2] Koh, K. M., Dong, F. M., and Tay Eng Guan. 2006. Intoduction to Graph Theory. Singapore: World Scientific.

[3] Munir, Rinaldi. 2007. Matematika Diskrit. Bandung: Informatika. 